\title{
Scheduling Additional Train Unit Services on Rail Transit Lines
}

\author{
Zhibin Jiang, ${ }^{1}$ Yuyan Tan, ${ }^{2}$ and Özgür Yalçınkaya ${ }^{3}$ \\ ${ }^{1}$ School of Transportation Engineering, Key Laboratory of Road and Traffic Engineering of the Ministry of Education, Tongji University, \\ 4800 Cao'an Road, Shanghai 201804, China \\ ${ }^{2}$ Institute of Railway Systems Engineering and Traffic Safety, Technical University of Braunschweig, Pockelsstraße 3, \\ 38106 Braunschweig, Germany \\ ${ }^{3}$ Department of Industrial Engineering, Dokuz Eylül University, 35160 Buca-Izmir, Turkey
}

Correspondence should be addressed to Yuyan Tan; y.tan@tu-bs.de

Received 4 June 2014; Accepted 31 July 2014; Published 25 September 2014

Academic Editor: Wuhong Wang

Copyright (C) 2014 Zhibin Jiang et al. This is an open access article distributed under the Creative Commons Attribution License, which permits unrestricted use, distribution, and reproduction in any medium, provided the original work is properly cited.

\begin{abstract}
This paper deals with the problem of scheduling additional train unit (TU) services in a double parallel rail transit line, and a mixed integer programming (MIP) model is formulated for integration strategies of new trains connected by TUs with the objective of obtaining higher frequencies in some special sections and special time periods due to mass passenger volumes. We took timetable scheduling and TUs scheduling as an integrated optimization model with two objectives: minimizing travel times of additional trains and minimizing shifts of initial trains. We illustrated our model using computational experiments drawn from the real rail transit line 16 in Shanghai and reached results which show that rail transit agencies can obtain a reasonable new timetable for different managerial goals in a matter of seconds, so the model is well suited to be used in daily operations.
\end{abstract}

\section{Introduction}

Transit scheduling is the processes of computing the frequency of services, the number of required vehicles, the timing of their travel, and other related operating elements. The outcomes of scheduling include graphical and numerical schedules for operators and supervisors, timetables for the public, and operating data for a line [1]. The rail transit timetable is aimed to meet the passenger demand, which varies during the hours of a day, the day of a week, from one season to another, and so forth [2]. On rail transit lines, due to the high frequencies and strict stock capacities in terminals, the timetable scheduling and the TUs scheduling should be considered simultaneously. Inserting some new train services into an initial timetable is one of the important methods in the process of redeveloping a timetable.

The primary motivation of this research based on additional demands occurrence in the rail transit lines of Shanghai. These additional demands, causing timetabling problems, have been determined by the Shanghai Shentong Metro Operation Company which is the responsible authority for the daily operations. The authority thinks it is an important problem and needed to be solved more efficiently, accurately, and fast. Up to March 2014, there have been 14 rail transit lines (with an operating route length of 538 kilometers and 329 stations) operated in Shanghai. On a normal weekday more than 8 million people use the Shanghai rail transit network. Planning of the rail transit operations primarily concerns the timetable and two other main resources: the rolling stocks and the crews. Planning of these resources undergoes two main phases (tactical and short-term planning) before the actual operation. The planning horizon in tactical planning is from one month up to one year. The steps conducted during this planning phase are constructing several initial timetables (for working days, weekend days, holidays, etc.) which satisfy different service demands and allocating the rolling stocks and the crews to the initial timetables. On the other hand, the short-term planning phase refers to planning tasks with a time horizon of a few days up to one month. In this phase the initial plans are adapted to the demands of the corresponding days. Special holidays and events that attract a lot of people, such as exhibitions, concerts, and major sports events, generally require an offered capacity in different times and positions. Consequently, some train services are required to be inserted 
to improve the capacity of some special sections with time windows. The most common way is inserting additional train services into the initial timetables.

The problem, which is called scheduling additional train unit services (SATUS) problem, is a problem in which new trains connected by a number of TUs start their trip from a depot or reversing tracks; after collectively visiting a number of routes, they return to the starting points. The SATUS problem is a complicated one, because the efficient circulation of TUs is an important consideration for operators of rail transit trains; additionally the large number of trips, links, and paths to be considered rapidly increases the number of variables and constraints in any model developed. The SATUS problem is not a real-time rescheduling problem, since the main difference between it and timetable rescheduling in short-term planning or in disruption management is the absence of uncertainty, and the fact that the latter is much less time-critical, while the first is often thought as a temporary redevelopment strategy of an initial timetable.

This paper deals with the problem of SATUS in a double parallel rail transit line, and a MIP model is formulated for integration strategies of new trains connected by TUs with the objective of obtaining higher frequencies in some special sections and special time periods due to mass passenger volumes.

The study contributes a number of new features to capture the influence of specific elements that have not been considered in studies on the SATUS problem in the related literature. First of all, the approach decides on timetables and TUs schedules using an integrated optimization model according to sections and turnback capacities. Second, a maximum deviation for arrival or departure times of trains in an initial timetable, all-station-stopping policy and express service strategy, linking orders, and time windows of new inserted trains are also considered. Finally, this model has two objectives: minimizing travel times of additional trains and minimizing shifts of initial trains.

The paper is organized as follows. In Section 2, a short review related to the SATUS problem is provided. After that, Section 3 introduces a brief summary of the relevant concepts in the model description. A MIP model, including sets, parameters, decision variables, and objective functions is presented in Section 4. Section 5 illustrates the proposed model with an example. The conclusions and future studies are summarized in Section 6.

\section{Literature Review}

The SATUS problem is related to a variety of topics in the literature. The first and foremost is railway transportation. Train scheduling, rescheduling, and routing problems have had a great deal of attention in recent years. There are two main timetable variants. One of the variants is the periodic (or cyclic) timetable that is repeated every given time period, for example, every hour, with only slight differences between peak hours and off-peak hours. The other variant is the nonperiodic timetable, which allows following the passenger demands with the frequencies of the trains. In both cases timetables are usually repeated every day, although there may be differences between weekdays and weekend.

Cacchiani et al. $[3,4]$ gave a detailed review of the literature on timetable scheduling. The timetable scheduling problem in a rail transit system, in which TUs, crews, and passengers are incorporated into a single planning framework science, is complex: various constraints and objectives should be considered simultaneously. Due to its importance and complexity, which have been acknowledged in various publications, topics related to this issue have attracted considerable attention in the literature. A multiphase, semiregular timetable, which divides a day into several time periods and even applies the vehicle-departing interval for each period, may somehow help to accommodate peak-hour demand while maintaining a certain level of service for passengers boarding at nonpeak hours. Guihaire and Hao [5] presented a global review of the crucial strategic and tactical steps of transit planning and also discussed the scheduling problem with phase regular for a transit corridor. Ceder [6] provided a comprehensive modeling framework for determining vehicle departure time with either even headways or even average loads, with a special focus on smoothing the transitions between time periods. These studies provide useful methods for optimizing frequency for a particular time period, while a unified framework is critically needed for scheduling methods that can consider uneven headways and time-dependent demand patterns. Jiang et al. $[7,8]$ presented a computational timetable scheduling method in rail transit line with multiroutes or circle route, and a timetable designing software named Train Plan Maker (TPM) was developed and applied by many metro operation companies in China. Niu and Zhou [9] focused on optimizing a passenger train timetable in a heavily congested urban rail corridor. A binary integer programming model incorporated with passenger loading and departure events was constructed to provide a theoretic description for the problem under consideration. Freyss et al. [10] focused on the skip-stop operation for rail transit lines using a single one-way track, and the system was modeled by using a continuous approximation approach.

Once the timetable scheduling has been defined, the rolling stock and TUs assignments must be done. An integer programming model was considered by Alfieri et al. [11] to determine the rolling stock circulation for multiple rolling stock types on a single line and on a single day, and this model was extended by Fioole et al. [12] by including combining and splitting trains, as it happens at several locations in the Dutch timetables. Cadarso et al. [13] studied the disruption management problem of rapid transit rail networks. Besides optimizing timetable and rolling stock schedules, they explicitly dealt with the effects of disruption on the passenger demands. They proposed a two-step approach that combines an integrated optimization model (for the timetable and the rolling stock) with a model for the behaviors of passengers. Lin and Kwan [14] proposed a two-phase approach for the TUs scheduling problem. The first phase assigned and sequenced train trips to TUs temporarily ignoring some station infrastructure details, which was modeled as an integer fixed-charge multicommodity flow (FCMF) problem. The second phase focused on satisfying the remaining station detailed requirements, which 
was modeled as a multidimensional matching problem with a mixed integer linear programming (MILP) formulation. Eberlein et al. [15] studied a real-time deadheading problem in transit operations control. Haghani and Banihashemi [16] proposed an innovative multiple depot vehicle scheduling with route time constraints (MDVSRTC) model to solve bus transit vehicle scheduling problems. After that they derived a single depot vehicle scheduling with route time constraints (SDVSRTC) model to solve the same problem [17]. Yu et al. [18] presented a partway deadheading strategy for transit operations to improve transit service of the peak directions of transit routes.

Inserting additional train into an existing timetable is a common technique used in railway systems. Burdett and Kozan [19] considered techniques for scheduling additional train services integrated into current timetables and involving general time window constraints, fixed operations, maintenance activities, and periods of section unavailability. Flier et al. [20] addressed the recurring problem of adding a train path, that is, a schedule for a single train in terms of track allocation in space and time, to a given dense timetable on a corridor which is an important subnetwork in form of a path between two major stations.

The SATUS problem includes the timetable scheduling and the TUs circulation problems; therefore it is usually much more complex and difficult to solve than the models dealing with a single phase. Cadarso and Marín [2] proposed an integrated MIP model to adapt the frequencies in a timetable together with rolling stock circulation in order to deal with increased passenger demands and traffic congestion in a rapid transit network. They also took into account the shunting of rolling stocks in depots. Canca et al. [21] proposed a tactical model to determine optimal policies of short-turning and nonstopping at certain stations, considering different objectives such as minimizing the passenger overload and preserving certain level of quality of service.

Our study contributes a number of new features to capture the influence of specific elements which have not been studied in the related literature as given in previous section.

\section{Problem Description}

In this section, the SATUS problem in rail transit lines is described in detail. Firstly, the rail transit line and the routes are introduced. After that, we describe the timetable and the TUs circulation problems. Then, headway and train traveling times are introduced, and finally, how the capacity of turnback operation is modeled has been explained.

3.1. Rail Transit Network and Route. The rail transit line with branch linking depots is considered to be a simple network with a collection of stations and sections, as illustrated in Figure 1. A rail transit network $G$ is defined by a set of stations $S$ that are connected to each other by a set of sections $B$. The rail transit line in the model consists of parallel double lines where trains follow a loop running from a certain station

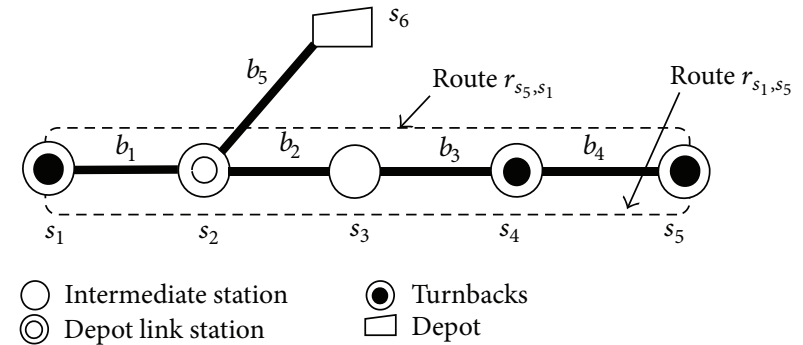

FIGURE 1: Rail transit line infrastructure definition.

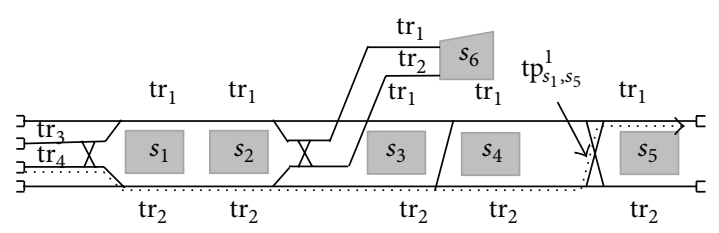

FIGURE 2: Train route infrastructure definition.

denoted as a starting point to an end station with right-hand running rule.

A train route is a group of trains that run bidirectional between two stations on the rail transit line. All trains in the same route have the same size, capacity, and operating characteristics and additionally they always visit the same sequence of stations. We define $r_{s_{i}, s_{j}}$ as a route linked by the stations $s_{i}$ and $s_{j}$. Rail transit line can be characterized by two main train route styles: (1) normal cyclic routes and (2) depot linking routes. The first one comprises the daily operations of fixed train cyclic running paths, with trains stopping and providing passenger loading services $\left(r_{s_{1}, s_{5}}, r_{s_{5}, s_{1}}, r_{s_{1}, s_{4}}\right.$, and $r_{s_{4}, s_{1}}$ in Figure 1). The latter refers to the route linking depot with a main turnback station, in which trains sometimes do not stop and cannot provide passenger services $\left(r_{s_{6}, s_{1}}, r_{s_{1}, s_{6}}\right.$, $r_{s_{6}, s_{2}}$, and $r_{s_{2}, s_{6}}$ in Figure 2).

A train track path is defined as the detailed train running path from an original station to a destination station, including the specified tracks in all stations. Let $s_{i}\left(\operatorname{tr}_{j}\right)$ describe the track $\operatorname{tr}_{j}$ of the station $s_{i}$; then the train track path from $s_{1}\left(\operatorname{tr}_{4}\right)$ to $s_{5}\left(\operatorname{tr}_{1}\right)$ in Figure 2 can be expressed by

$\operatorname{tp}_{s_{1}, s_{5}}^{1}=\left\{s_{1}\left(\operatorname{tr}_{4}\right), s_{1}\left(\operatorname{tr}_{2}\right), s_{2}\left(\operatorname{tr}_{2}\right), s_{3}\left(\operatorname{tr}_{2}\right), s_{4}\left(\operatorname{tr}_{2}\right), s_{5}\left(\operatorname{tr}_{1}\right)\right\}$.

3.2. Timetable and TUs Circulation. In rail transit lines, a time-distance diagram has the line (distance) plotted on the vertical and time on the horizontal axes. As shown in Figure 3 , the line is divided in sections with uniform speeds. The plot of every run of a train and TUs, indicated by a number, shows all scheduled elements (travel time, speed, etc.) of the train on each section and at each terminal. The horizontal axis also shows headways as time distances between subsequent train runs and cycle time $\left(T_{c}\right)$ as time distances between two successive departures related to the 


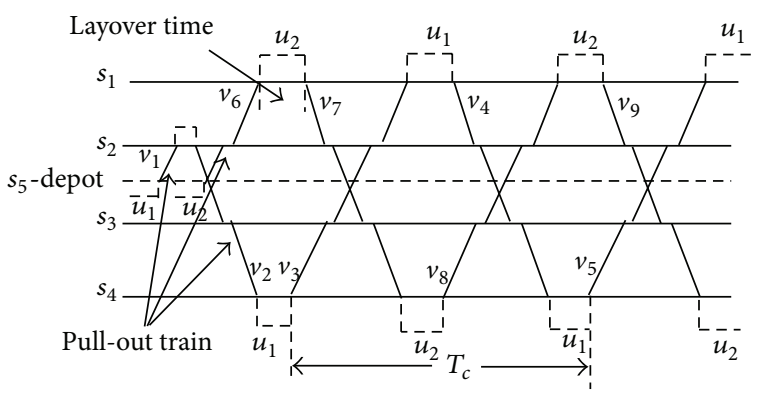

FIgURE 3: Time-distance diagram for a rail transit line.

same TUs from a terminal. The whole diagram shows train arrivals/departures at each reference point along the line, layover time, as well as locations and times where trains meet. Time-distance diagram can also show pull-outs and pullins of trains from depots for operations on some sections, different stopping times, and so forth.

In our model, the set of trains considered is given by $T=$ $T^{\text {ini }} \cup T^{\text {add }}$, where $T^{\text {ini }}$ denotes the set of initial trains that have a prescribed timetable and $T^{\text {add }}$ denotes the set of additional trains that need to be inserted to the original timetable.

For each train $i \in T^{\mathrm{ini}}$, a timetable is specified, consisting of the following:

(i) an ordered sequence of trains $t_{i}$,

(ii) an ordered sequence of TUs $U_{j}$,

(iii) an ordered sequence of trains linked by TU $j$ and $u_{j}:=$ $\left\{t_{i}, \ldots, t_{p}\right\}$

(iv) an ordered sequence of stations $S^{i}:=\left\{f_{i}, \ldots, l_{i}\right\} \in S$ that the train $i$ visits, where $f_{i}$ is the first (origin) station and $l_{i}$ is the last (destination) station,

(v) the departure time from $f_{i}$, the arrival time to $l_{i}$, and the arrival and departure times for the intermediate stations in $S^{i} \backslash\left\{f_{i}, l_{i}\right\}$ of the train $i$,

(vi) the exact track path $k_{i}$ that is allocated to the train $i$ on each station,

(vii) the maximum deviation for arrival or departure times of trains,

(viii) the minimum and the maximum dwell times at each station in $S^{i} \backslash\left\{f_{i}, l_{i}\right\}$ and the trip time at each section $b=\left\{j, j^{\prime}\right\}$, with $j, j^{\prime} \in S^{i}$.

For each train $i \in T^{\text {add }}$, a timetable is specified, consisting of the following:

(i) a sequence of TUs $u_{j}^{\text {add }}$,

(ii) an ordered sequence of new trains $t_{i}^{\text {add }}$,

(iii) an ordered sequence of trains linked by TU $j$ and $u_{j}^{\text {add }}:=\left\{t_{i}^{\text {add }}, \ldots, t_{p}^{\text {add }}\right\}$,

(iv) an ordered sequence of stations $S^{i}:=\left\{f_{i}, \ldots, l_{i}\right\} \in S$ that the train $i$ visits, where $f_{i}$ is the first (origin) station and $l_{i}$ is the last (destination) station,

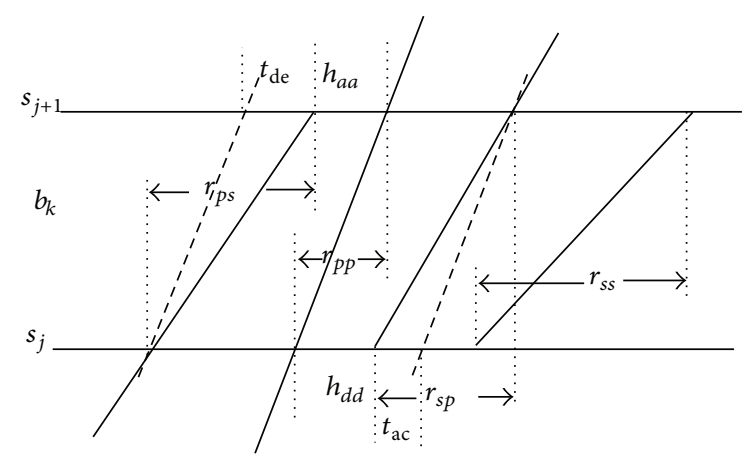

FIGURE 4: Illustration of headways and train traveling times.

(v) the exact track path $k_{i}$ that is allocated to the train $i$ on each station,

(vi) the desired departure time window from $f_{i}$, the minimum and the maximum dwell times at each station in $S^{i} \backslash\left\{f_{i}, l_{i}\right\}$, and the trip time at each section $b=\left\{j, j^{\prime}\right\}$, with $j, j^{\prime} \in S^{i}$.

3.3. Headways and Train Traveling Times. The minimum headway on a line is determined by the physical characteristics of the system (technology, methods of driving and control, and required degree of safety) and station operations (rate of boarding/alighting, departure control, etc.). In our model, we consider the express service strategy, so the headways need to be defined separately for departing and arriving. Set $h_{d d}$ to be the minimum headway of two successive trains departing from stations and $h_{a a}$ the minimum headway of two successive trains arriving to stations, as shown in Figure 4. Each time when an intermediate station is passed by a train, the spent times in decelerating, stopping, and accelerating of the vehicle are saved at the successive station. So this model considers acceleration time $\left(t_{\mathrm{ac}}\right)$ and deceleration time $\left(t_{\mathrm{de}}\right)$, as shown in Figure 4 . There are four execution modes for train traveling at section $b_{k}$, namely, (1) bypassing stations $s_{j}$ and $s_{j+1}\left(r_{p p}\right)$, (2) bypassing station $s_{j}$ but stopping at station $s_{j+1}\left(r_{p s}\right)$, (3) stopping at station $s_{j}$ but bypassing station $s_{j+1}\left(r_{s p}\right)$, and (4) stopping at both stations $s_{j}$ and $s_{j+1}\left(r_{s s}\right)$. So $r_{p s}, r_{s p}$, and $r_{s s}$ can be calculated by the following, respectively:

$$
\begin{gathered}
r_{p s}=r_{p p}+t_{\mathrm{de}}, \\
r_{s p}=r_{p p}+t_{\mathrm{ac}}, \\
r_{s s}=r_{p p}+t_{\mathrm{ac}}+t_{\mathrm{de}} .
\end{gathered}
$$

3.4. Layover Time and Turnback Operation. Layover time is the time between the scheduled arrival and departure of a vehicle at a transit terminal. Minimum layover time includes the dwell time for alighting and boarding of passengers, the time for changing the train operator and conducting any necessary inspections and brake tests, and the time for moving and locking the crossover switches and the time for recovery of the schedule if it is needed. Maximum layover 


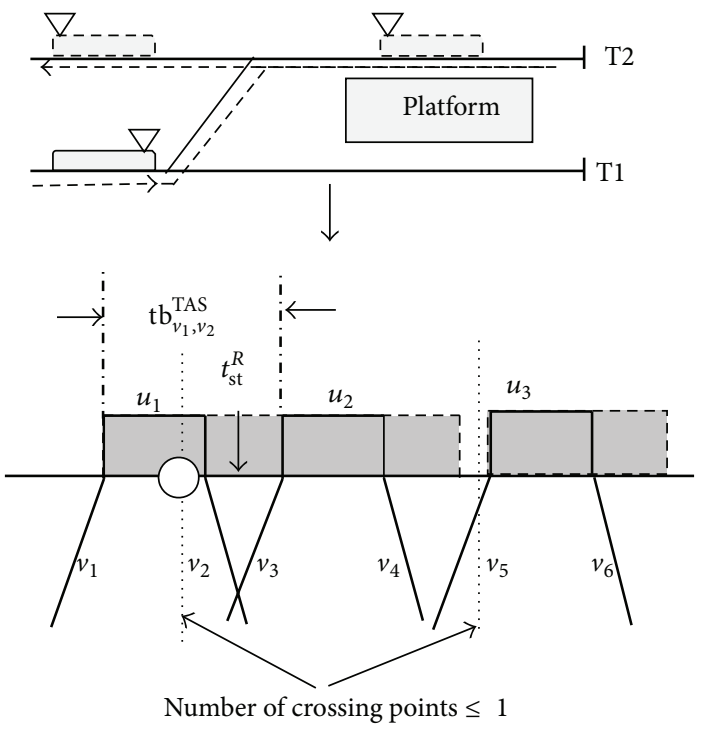

(a) Turnback operation with crossover located in advance of a station (TAS)

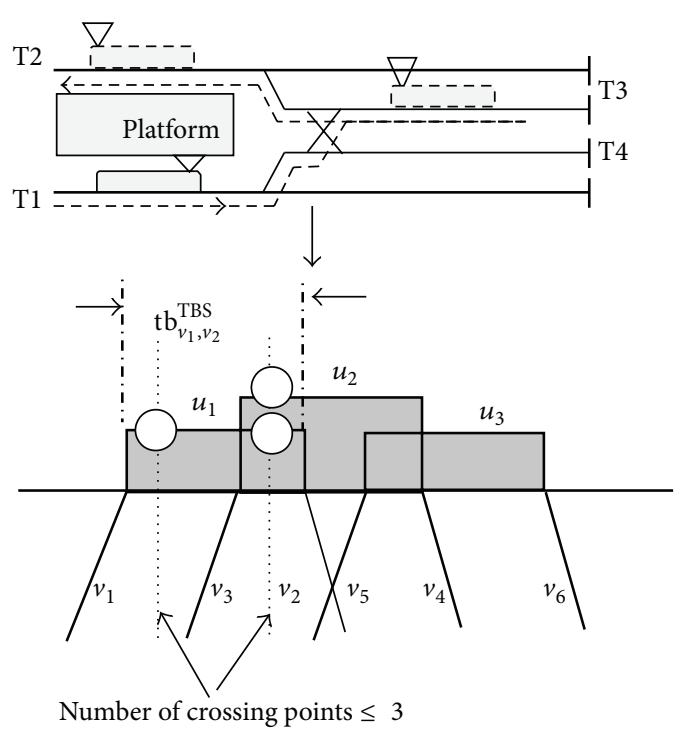

(b) Turnback operation with crossover located in back of a station (TBS)

FIGURE 5: Track occupation of turnback operation process at a terminal.

time is a function of terminal capacity (number of reversing tracks and platform clearance time) and train arrival rate.

There are two typical turnback operations according to the terminal types: turnback operation with crossover located in (1) advance of a station (TAS) and (2) back of a station (TBS), as illustrated in Figure 5. On the condition of TAS, if all trains occupy the same turnback track, the second arriving train $\left(v_{3}\right.$ in Figure 5(a)) arrival to the station must insure that the first departing train $\left(v_{2}\right.$ in Figure 5(a)), which linked with the first arrival train $\left(v_{1}\right.$ in Figure 5(a)), has left from the station. Let $t_{\mathrm{st}}^{R}$ be the minimum separation time of trains that are occupying the same turnback track; the occupation time of each train pair $\left(v_{i}, v_{j}\right)$, in which the train $v_{i}$ and the consecutive train $v_{j}$ share the same TUs, at a terminal can be calculated by

$$
\mathrm{tb}_{v_{i}, v_{j}}^{\mathrm{TAS}} \in\left[t_{v_{i}}^{a}, t_{v_{j}}^{d}+t_{\mathrm{st}}^{R}\right]
$$

where $t_{v_{i}}^{a}, t_{v_{j}}^{d}$ are the arrival time of train $v_{i}$ and the departure time of train $v_{j}$ at the terminal, respectively. So the capacity constraint with TAS can be transferred to this problem: at any time, the number of TUs (same value of the number of crossing points, as shown in Figure 5(a)) staying in a terminal cannot be more than one.

On the other hand, on the condition of TBS, the arriving train pulls into one platform and then pulls into one of the tail tracks, changes direction, and then returns to pick up passengers from the other platform. So there is no conflict between departing and arriving trains. But the maximum number of existing TUs at any time in the terminal depends on the number of tail tracks. So the capacity constraint with TBS turnback operation can be transferred to this problem: at any time, the number of TUs staying in a terminal cannot be more than three (only one tail track can be selected), as shown in Figure 5(b). And the occupation time of each train pairs $\left(v_{i}, v_{j}\right)$ at the terminal can be calculated by

$$
\mathrm{tb}_{v_{i}, v_{j}}^{\mathrm{TBS}} \in\left[t_{v_{i}}^{a}, t_{v_{j}}^{d}\right] .
$$

\section{Model Description}

The model of the SATUS problem is developed as a MIP model. It aims at computing a new timetable accompanied with a TUs schedule for a rail transit line and balances several objective criterions.

4.1. Sets. The sets below contain the basic information for our mathematical model:

$S$ : set of stations in the rail transit line,

$B$ : set of sections between two stations $b=\left(s_{i}, s_{j}\right)$ in the rail transit line, with $s_{i}, s_{j} \in S$,

$S^{T}$ : set of turnback stations,

$T=T^{\text {ini }} \cup T^{\text {add }}$ : set of all trains, consisting of additional trains $T^{\text {add }}$ and initial trains $T^{\text {ini }}$,

$U=U^{\text {ini }} U U^{\text {add }}$ : set of all TUs, consisting of additional TUs $U^{\text {add }}$ and initial TUs $U^{\text {ini }}$,

$R^{j}$ : set of all train pairs $\left(i, i^{\prime}\right)$, with $i<i^{\prime}$, when the train $i$ and the consecutive train $i^{\prime}$ share the same TUs at the station $j, i, i^{\prime} \in T, j \in S^{T}$,

$S^{i} \in S$ : set of stations that the train $i$ visits,

$B^{i} \in B$ : set of sections that the train $i$ travels along,

$P$ : set of time slot in the planning horizon, 
$f_{i}$ : set of first (starting) travelling station of the train $i, i \in T$,

$l_{i}$ : set of last (ending) travelling station of the train $i$, $i \in T$.

4.2. Parameters. The model uses the following parameters, which are all assumed to be integer valued:

$t_{H}^{\min }$ : the minimum time of the planning horizon,

$t_{H}^{\max }$ : the maximum time of the planning horizon,

$x_{i, j}^{a, \text { ini }}:$ the departure time of the train $i$ from the station $j, i \in T^{\mathrm{ini}}, j \in S^{i}$

$x_{i, j}^{d, \text { ini }}:$ the arrival time of the train $i$ at the station $j$, $i \in T^{\mathrm{ini}}, j \in S^{i}$,

$h_{d d}$ : the minimum headway time between two consecutive departures,

$h_{a a}$ : the minimum headway time between two consecutive arrivals,

$t_{\mathrm{ac}}$ : the acceleration time,

$t_{\mathrm{de}}$ : the deceleration time,

$r_{b}$ : the traveling time of a train without any stops at stations $s_{i}$ and $s_{j}, b=\left(s_{i}, s_{j}\right) \in B$,

$\mathrm{dw}_{i, j}^{\min }:$ the minimum dwell time of the train $i$ if it has a loading service at the station $j, i \in T, j \in S$; $=0$, otherwise,

$\mathrm{dw}_{i, j}^{\max }$ : the maximum dwell time of the train $i$ at the station $j, i \in T, j \in S^{i}$,

$C_{j}^{\min }$ : the minimum layover time at the terminal $j, j \in$ $S^{T}$,

$C_{j}^{\max }$ : the maximum layover time at the terminal $j, j \in$ $S^{T}$,

M: a sufficiently large positive constant (here given the value $3600 \times 24$, that is, the length of the largest considered time horizon in seconds),

$\lambda_{i, i^{\prime}}$ : binary variable $=1$, if the train $i^{\prime}$ shares the same TUs after the end of the train $i, i, i^{\prime} \in T, j \in S^{T},\left(i, i^{\prime}\right) \in$ $R^{j}$; $=0$, otherwise,

$t c_{j}$ : the maximum number of TUs at the same time at the terminal $j, j \in S^{T}$,

$t_{\max S}^{\text {ini }}$ : the maximum deviation of arrival or departure times of the initial train $i, i \in T^{\text {ini }}$.

4.3. Decision Variables. The following variables are used in the model:

$x_{i, j}^{a}:$ the departure time of the train $i$ at the station $j$, $i \in T, j \in S^{i}$,

$x_{i, j}^{d}$ : the arrival time of the train $i$ at the station $j, i \in T$, $j \in S^{i}$, $\varphi_{i, j}:$ binary variable $=1$, if the train $i$ stops at the station $j, i \in T, j \in S^{i} ;=0$, otherwise,

$\pi_{i, i^{\prime}, j}^{d}$ : binary variable $=1$, if the train $i$ departures before the train $i^{\prime}$ at the station $j, i, i^{\prime} \in T, j \in S^{i}$; $=0$, otherwise,

$\pi_{i, i^{\prime}, j}^{a}$ : binary variable $=1$, if the train $i$ arrives before the train $i^{\prime}$ at the station $j, i, i^{\prime} \in T, j \in S^{i} ;=0$, otherwise,

$\theta_{p, r, j}$ : binary variable $=1$, if the time slot $p$ is within the occupation time (see (3) and (4)) of the train pairs $r$ at the terminal $j, p \in P, j \in S^{T}, r=\left(i, i^{\prime}\right) \in R^{j}, i, i^{\prime} \in T$; $=0$, otherwise,

$n_{p, j}^{\mathrm{TU}}$ : the number of TUs at the station $j$ in the time slot $p, j \in S^{T}, p \in P$.

4.4. Objective Functions. We consider two different objectives in the view of the following two aspects:

(1) high quality for the operation of additional trains, which can be represented by minimizing the travel time of the additional trains

$$
\begin{gathered}
\min F_{t}, \\
F_{t}=\sum_{i \in T^{\text {add }}}\left(x_{i, l_{i}}^{a}-x_{i, f_{i}}^{d}\right),
\end{gathered}
$$

(2) less deviation to existing trains in the original timetable, this can be represented by minimizing the shift of the initial trains

$$
F_{s}=\sum_{i \in T^{\mathrm{ini}}, j \in S^{i}}\left[\left|\left(x_{i, j}^{a}-x_{i, j}^{a, \text { ini }}\right)\right|+\left|\left(x_{i, j}^{d}-x_{i, j}^{d, \text { ini }}\right)\right|\right] .
$$

4.5. Constraints. In this section, we will focus on the constraints associated with the SATUS problem; they are listed as follows.

4.5.1. Timetable Constraints. Consider the following:

$$
\begin{array}{r}
x_{i, j^{\prime}}^{a}=x_{i, j}^{d}+r_{b}+t_{a a} \cdot \varphi_{i, j}+t_{a d} \cdot \varphi_{i, j^{\prime}}, \\
b=\left(j, j^{\prime}\right) \in B^{i}, \quad i \in T, \\
x_{i, j}^{d}-x_{i, j}^{a} \geq \mathrm{dw}_{i, j}^{\min } \cdot \varphi_{i, j}, \quad i \in T, \quad j \in S^{i}, \\
x_{i, j}^{d}-x_{i, j}^{a} \leq \operatorname{dw}_{i, j}^{\max } \cdot \varphi_{i, j}, \quad i \in T, \quad j \in S^{i} .
\end{array}
$$

Constraints (7) define the arrival time to the station $j^{\prime}$ from the departure time at the station $j$ adding the traveling time at section $b$, which includes the bypassing running time $\left(r_{b}\right)$, the acceleration time (if a train stops at the station $j$ ), and the deceleration time (if a train stops at the station $j^{\prime}$ ). At each station, the dwell time at the station should not be less than the minimum dwell time and not be more than the maximum dwell time if the train needs to stop. This fact is depicted in constraints (8) and (9). 
4.5.2. Headway Constraints. Consider the following:

$$
\begin{array}{r}
x_{i, j}^{d}-x_{i^{\prime}, j}^{d} \geq h_{d d} \cdot \pi_{i, i^{\prime}, j}^{d}-M \cdot\left(1-\pi_{i, i^{\prime}, j}^{d}\right), \\
i, i^{\prime} \in T, \quad j \in S^{i}, \\
x_{i^{\prime}, j}^{d}-x_{i, j}^{d} \geq h_{d d} \cdot\left(1-\pi_{i, i^{\prime}, j}^{d}\right)-M \cdot \pi_{i, i^{\prime}, j^{\prime}}^{d}, \\
\quad i, i^{\prime} \in T, \quad j \in S^{i}, \\
x_{i, j}^{a}-x_{i^{\prime}, j}^{a} \geq h_{a a} \cdot \pi_{i, i^{\prime}, j}^{a}-M \cdot\left(1-\pi_{i, i^{\prime}, j}^{a}\right), \\
\quad i, i^{\prime} \in T, \quad j \in S^{i}, \\
x_{i^{\prime}, j}^{a}-x_{i, j}^{a} \geq h_{a a} \cdot\left(1-\pi_{i, i^{\prime}, j}^{a}\right)-M \cdot \pi_{i, i^{\prime}, j}^{a}, \\
\quad i, i^{\prime} \in T, \quad j \in S^{i}, \\
\pi_{i, i^{\prime}, j^{\prime}}^{a}=\pi_{i, i^{\prime}, j}^{d}, \quad b=\left(j, j^{\prime}\right) \in B^{i}, \quad i, i^{\prime} \in T, \\
\pi_{i, i^{\prime}, j}^{d}=\pi_{i, i^{\prime}, j}^{a}, \quad j \in S^{i}, i, i^{\prime} \in T .
\end{array}
$$

The headway constraints (10)-(13) describe the minimum headway requirements between the departure time and the arrival time of the consecutive trains at the same station. Constraints (14) and (15) enforce the order of the consecutive trains in all sections meaning that a train is not allowed to overtake another train.

\subsubsection{Time Deviation Constraints. Consider the following:}

$$
\begin{aligned}
& x_{i, j}^{a}-x_{i, j}^{a, \text { ini }} \in\left[-t_{\max S}^{\mathrm{ini}}, t_{\max S}^{\mathrm{ini}}\right], \\
& b=\left(j, j^{\prime}\right) \in B^{i}, \quad j \in S^{i}, i \in T, \\
& x_{i, j}^{d}-x_{i, j}^{d, \text { ini }} \in\left[-t_{\max S}^{\mathrm{ini}}, t_{\max S}^{\mathrm{ini}}\right], \\
& b=\left(j, j^{\prime}\right) \in B^{i}, \quad j \in S^{i}, i \in T .
\end{aligned}
$$

Constraints (16) define the deviation for the arrival or departure times of a train from its preferred arrival or departure times in the initial timetable.

\subsubsection{Layover Time and Turnback Operation Constraints.} Consider the following:

$$
\begin{gathered}
x_{i^{\prime}, j}^{d}-x_{i, j}^{a} \in\left[C_{j}^{\min }, C_{j}^{\max }\right], \\
\left(i, i^{\prime}\right) \in R^{j}, \quad j \in S^{i}, i, i^{\prime} \in T, \\
n_{p, j}^{\mathrm{TU}}=\sum_{r=\left(i, i^{\prime}\right) \in R^{j}} \theta_{p, r, j}, \\
p \in P, \quad j \in S^{T}, \quad i, i^{\prime} \in T, \\
n_{p, j}^{\mathrm{TU}} \leq t c_{j}, \quad p \in P, \quad j \in S^{T} .
\end{gathered}
$$

Constraints (17) determine the minimum and the maximum layover times between two consecutive trains linked by the same TU at the same station. In (18) the total number of TUs is calculated on the condition that the time slot $p$ is within the occupation time of the train pairs $r$ at the terminal $j$ (see Figure 5). Constraints (19) indicate that the total number of TUs in the time slot $p$ at the terminal $j$ must be equal to or less than the given value based on turnback operation style.

\section{Computational Experiments}

5.1. Simulation Example. Our experiments are based on real cases drawn from Shanghai rail transit line 16. This line is $52.85 \mathrm{~km}$ long, composed of one main line and one depot linking line, with 11 stations and one depot. This line has double tracks on all sections, as shown in Figure 6. It is the unique rail transit line in Shanghai that has two different stopping services: (1) slow services in which trains stop at all stations and (2) express services in which trains stop only at LSR, XC, HN, and DSL stations.

We implemented the models in Visual Studio 2012 using IBM ILOG CPLEX 12.5 as a black-box MIP solver and running on a personal computer with an Intel Core i7-3520M $\mathrm{CPU}$ at $2.90 \mathrm{GHz}$ and $4 \mathrm{~GB}$ of RAM. This model was run under Windows 8 64-Bit, and default solver values were used for all parameters. The new time-distance diagram obtained from computation can be displayed by the train plan maker (TPM) software $[7,8]$. In order to reduce the scale of the variant and the computation time, in our model, the time step (e.g., every $1 \mathrm{sec}, 5 \mathrm{sec}, 10 \mathrm{sec}, 30 \mathrm{sec}$, and $60 \mathrm{sec}$ ) can be defined by the users. In this case, we define the time step as $30 \mathrm{sec}$ and all the time lengths in parameters are the integer multiple of $30 \mathrm{sec}$.

The initial timetable is an actual weekday operation timetable of the line 16 in March 2014. This timetable, which is named 1601-2, is operated in the interval of $10 \mathrm{~min}$ by the cyclic trips between LSR and DSL. In this case, the planning horizon is defined from 5:00 to 10:00 o'clock, covering the morning peak hours with 56 trains and 12 TUs. Additionally, the possibility of attending 10 different train routes and track paths into initial and additional timetables is considered. These routes and track paths are defined by their original station, destination station, and occupied tracks in every station, as shown in Table 1. The turnback operation mode in EHN and DSL is TAS, and on the other hand in DSL is TBS.

The computation parameters, additional trains with one TU linking, and time windows of the new trains are defined in Tables 2, 3, and 4 .

5.2. Scenarios. In our computation analysis 10 scenarios are studied, and each of them differs from the others mainly in the points of (1) objective function and (2) maximum deviation in the arrival or departure times of the initial trains. The value of maximum deviation should not be too much (better to use less than half of the headways) because the initial timetable is regularly used by commuter passengers, and if there is a big change in it, it may cause inconvenience for the passengers. Within these scenarios, we also change 


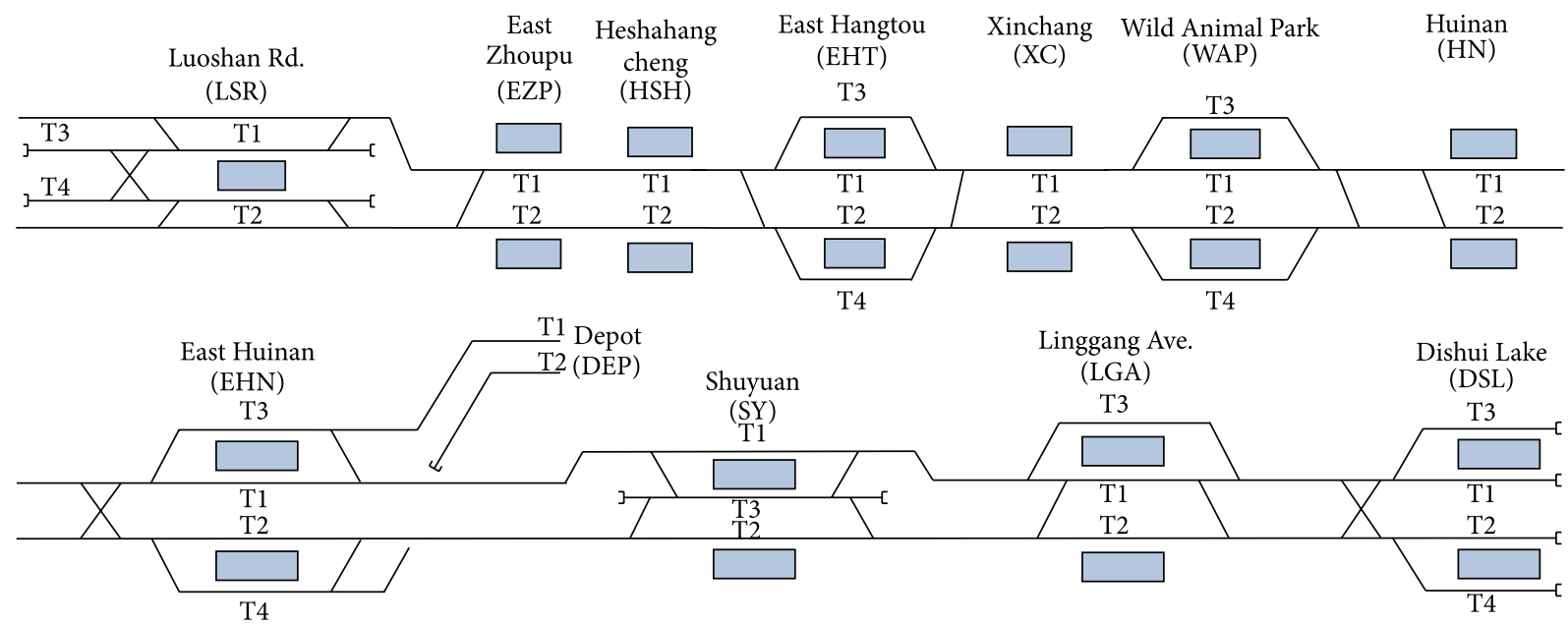

FIGURE 6: Infrastructure of Shanghai rail transit line 16.

TABLE 1: Train routes and track path information in line 16.

\begin{tabular}{|c|c|c|c|}
\hline Route ID & Route information & Route track path ID & Detail track path information \\
\hline $\mathrm{R} 1$ & $\mathrm{LSR} \rightarrow \mathrm{DSL}$ & R1-1 & $\begin{array}{l}\text { LSR }(\mathrm{T} 4, \mathrm{~T} 2) \rightarrow \text { DSL }(\mathrm{T} 1), \mathrm{T} 4 \text { in EHT, WAP and EHN, } \\
\text { T2 in the other stations }\end{array}$ \\
\hline $\mathrm{R} 2$ & $\mathrm{DSL} \rightarrow \mathrm{LSR}$ & $\mathrm{R} 2-1$ & $\begin{array}{l}\text { DSL }(\mathrm{T} 1) \rightarrow \text { LSR }(\mathrm{T} 1-\mathrm{T} 4), \mathrm{T} 3 \mathrm{in} \mathrm{EHT}, \mathrm{WAP} \text { and } \mathrm{EHN} \text {, } \\
\mathrm{T} 1 \text { in the other stations }\end{array}$ \\
\hline R3 & $\mathrm{DEP} \rightarrow \mathrm{EHN}$ & R3-1 & $\mathrm{DEP}(\mathrm{T} 2) \rightarrow \mathrm{EHN}(\mathrm{T} 4)$ \\
\hline $\mathrm{R} 4$ & $\mathrm{EHN} \rightarrow \mathrm{DEP}$ & R4-1 & $\mathrm{EHN}(\mathrm{T} 3) \rightarrow \mathrm{DEP}(\mathrm{T} 1)$ \\
\hline R5 & $\mathrm{EHN} \rightarrow \mathrm{DSL}$ & R5-1 & EHN (T4) $\rightarrow$ DSL (T1), T2 in the other stations \\
\hline R6 & $\mathrm{DSL} \rightarrow \mathrm{EHN}$ & R6-1 & DSL (T1) $\rightarrow$ EHN (T3), T1 in the other stations \\
\hline R7 & $\mathrm{DEP} \rightarrow \mathrm{LSR}$ & $\mathrm{R} 7-1$ & $\begin{array}{l}\mathrm{DEP}(\mathrm{T} 1) \rightarrow \mathrm{EHN}(\mathrm{T} 3) \rightarrow \mathrm{LSR}(\mathrm{T} 1, \mathrm{~T} 4), \mathrm{T} 3 \mathrm{in} \mathrm{EHT} \\
\text { WAP, T1 in the other stations }\end{array}$ \\
\hline R8 & $\mathrm{LSR} \rightarrow \mathrm{DEP}$ & R8-1 & $\begin{array}{l}\mathrm{LSR}(\mathrm{T} 4, \mathrm{~T} 2) \rightarrow \mathrm{EHN}(\mathrm{T} 4) \rightarrow \mathrm{DEP}(\mathrm{T} 2), \mathrm{T} 4 \text { in } \mathrm{EHT} \\
\text { WAP, T2 in the other stations }\end{array}$ \\
\hline R9 & $\mathrm{LSR} \rightarrow \mathrm{EHN}$ & R9-1 & $\begin{array}{l}\mathrm{LSR}(\mathrm{T} 4, \mathrm{~T} 2) \rightarrow \mathrm{EHN}(\mathrm{T} 3), \mathrm{T} 4 \text { in } \mathrm{EHT}, \mathrm{WAP}, \mathrm{T} 2 \text { in the } \\
\text { other stations }\end{array}$ \\
\hline R10 & $\mathrm{EHN} \rightarrow \mathrm{LSR}$ & R10-1 & $\begin{array}{l}\mathrm{EHN}(\mathrm{T} 3) \rightarrow \mathrm{LSR}(\mathrm{T} 1, \mathrm{~T} 4), \mathrm{T} 3 \text { in EHT, WAP, T1 in the } \\
\text { other stations }\end{array}$ \\
\hline
\end{tabular}

TABLE 2: Computation parameters in line 16.

\begin{tabular}{lc}
\hline Parameter & Value \\
\hline$t_{H}^{\min }$ & $5: 00$ \\
$t_{H}^{\max }$ & $10: 00$ \\
$h_{d d}$ & $180 \mathrm{sec}$ \\
$h_{a a}$ & $180 \mathrm{sec}$ \\
$t_{\mathrm{ac}}$ & $30 \mathrm{sec}$ \\
$t_{\mathrm{de}}$ & $30 \mathrm{sec}$ \\
$\mathrm{dw}_{i, j}^{\min }$ & $30 \mathrm{sec}$ \\
$\mathrm{dw}_{i, j}^{\max }$ & $60 \mathrm{sec}$ \\
$C_{j}^{\min }$ & DSL (180 sec $),$ LSR $(270 \mathrm{sec}), \mathrm{EHN}(60 \mathrm{sec})$ \\
$C_{j}^{\max }$ & $600 \mathrm{sec}$ \\
$t c_{j}$ & 2 at DSL, 1 at LSR and EHN \\
\hline
\end{tabular}

the time window of starting time for the new trains. Table 5 summarizes the studied scenarios.

5.3. Results. Table 6 exhibits the computational results of the scenarios carried out on the rail transit line 16 in Shanghai with parameters and inputs defined as explained above. The solution times are less than 1 minute.

As summarized in Table 6, the scenarios 1 and 2 have the same objective value and the computational times are not very high. Inserting the new trains to the initial timetable is mainly restricted by the departure and arrival headways since the initial trains are fixed and the express trains cannot overtake all the other trains. Figures 7 and 8 show the timedistance diagram obtained by scenarios 1 and 2 , respectively, in which inserting the new trains linked by $\mathrm{U} 2$ to the initial 
5:00 5:10 5:20 5:30 5:40 5:50 6:00 6:10 6:20 6:30 6:40 6:50 7:00 7:10 7:20 7:30 7:40 7:50 8:00 8:10 8:20 8:30 8:40 8:50 9:00

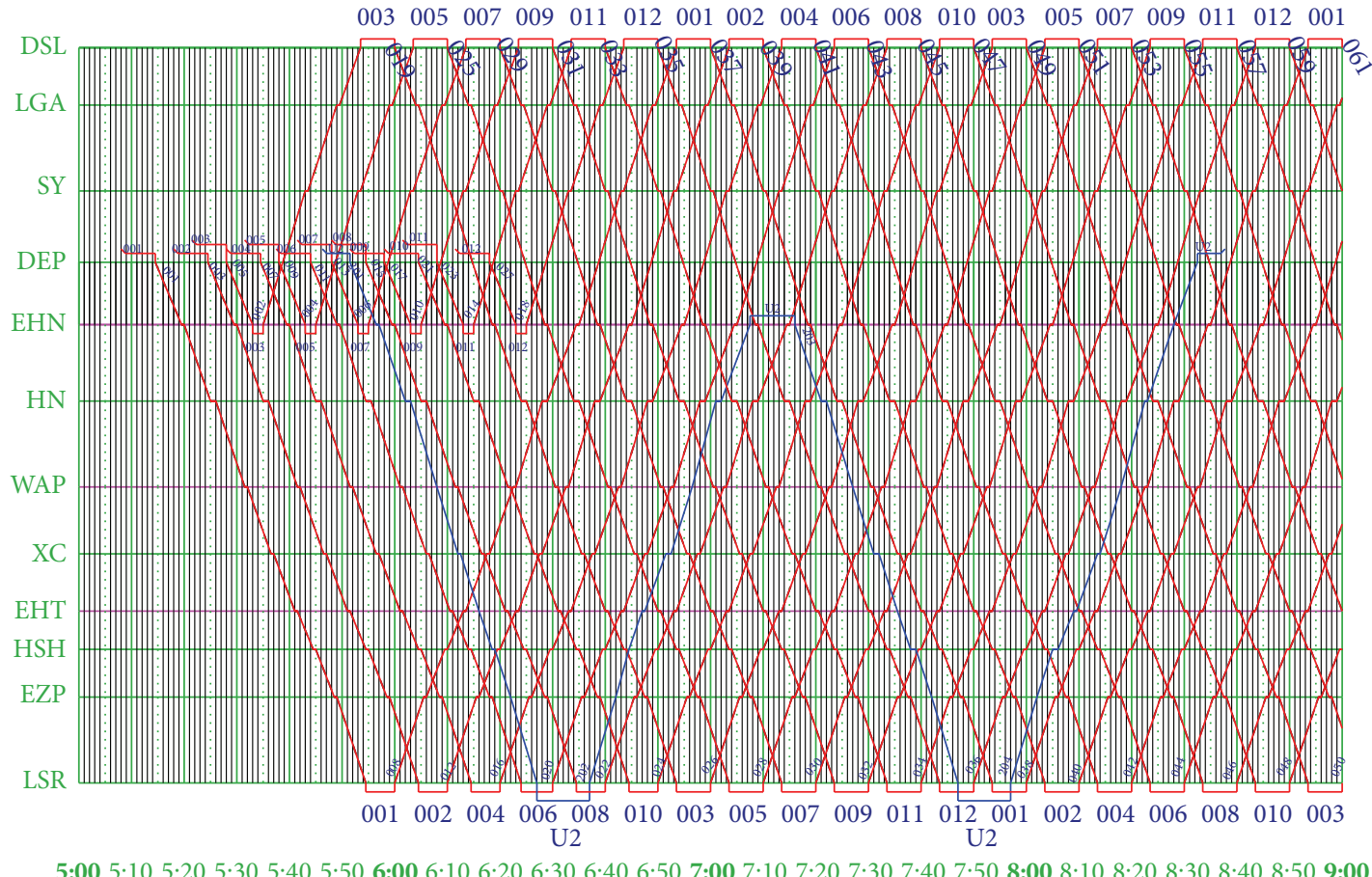

FIGURE 7: Time-distance diagram obtained by the scenario 1.

TABLE 3: Parameters of the new trains with one TU linking.

\begin{tabular}{lccccl}
\hline New TU ID & Train sequence & Train number & Route ID & Track path ID & Stopping scheme \\
\hline U1 & 1 & 101 & R3 & R3-1 & \\
U1 & 2 & 102 & R5 & R5-1 & \\
U1 & 3 & 103 & R2 & R2-1 & Original and destination stations $(60 \mathrm{sec})$, \\
U1 & 4 & 104 & R3 & R3-1 & HN $(45 \mathrm{sec})$, and other stations $(30 \mathrm{sec})$ \\
U1 & 5 & 105 & R6 & R6-1 & \\
U1 & 6 & 106 & R4 & R4-1 & \\
\hline U2 & 1 & 201 & R7 & R7-1 & Original and destination stations $(60$ sec), \\
U2 & 2 & 202 & R9 & R9-1 & XC \& HN $(30$ sec), and other stations \\
U2 & 3 & 203 & R10 & R10-1 & $(0 \mathrm{sec})$ \\
U2 & 4 & 204 & R8 & R8-1 & \\
\hline
\end{tabular}

TABLE 4: Time windows of the new trains.

\begin{tabular}{lc}
\hline \multicolumn{1}{l}{ Time window scheme ID } & Time window \\
\hline TW1 & Train "101": 5:30-6:00, others: $5: 00-10: 00$ \\
TW2 & Train "103": 6:00-6:10, others: 5:00-10:00 \\
TW3 & Train "201": 5:30-6:00, others: 5:00-10:00 \\
TW4 & Train "202": 6:00-6:10, others: $5: 00-10: 00$ \\
\hline
\end{tabular}

timetables results in the same total traveling times. And all the new trains cause some additional stopping times at some stations. For instance let us look at train "201" in scenario 1; as seen additional stops at EHN (30 sec) and $\mathrm{HSH}(30 \mathrm{sec})$ have happened, and the stopping time at $\mathrm{HN}$ is $60 \mathrm{sec}$, which is longer than the scheduled one (30 sec).

The objective values in scenarios 3 and 4 are different, and it is noticed that scenario 3 needs a higher computation time due to the wider time window for the pull-out train "201." Figures 9 and 10 illustrate the time-distance diagram obtained by scenarios 3 and 4, respectively; the actual effected trains and moving time from the initial timetable are quite different because of the fact that the start time windows of the new trains are different. The restrictions of the headway and the turnback capacity (at DSL) cause some trains to move forward or backward and cause more dwell times at some stations. 
5:00 5:10 5:20 5:30 5:40 5:50 6:00 6:10 6:20 6:30 6:40 6:50 7:00 7:10 7:20 7:30 7:40 7:50 8:00 8:10 8:20 8:30 8:40 8:50 9:00

$\begin{array}{lllllllllllllllllll}003 & 005 & 007 & 009 & 011 & 012 & 001 & 002 & 004 & 006 & 008 & 010 & 003 & 005 & 007 & 009 & 011 & 012 & 001\end{array}$

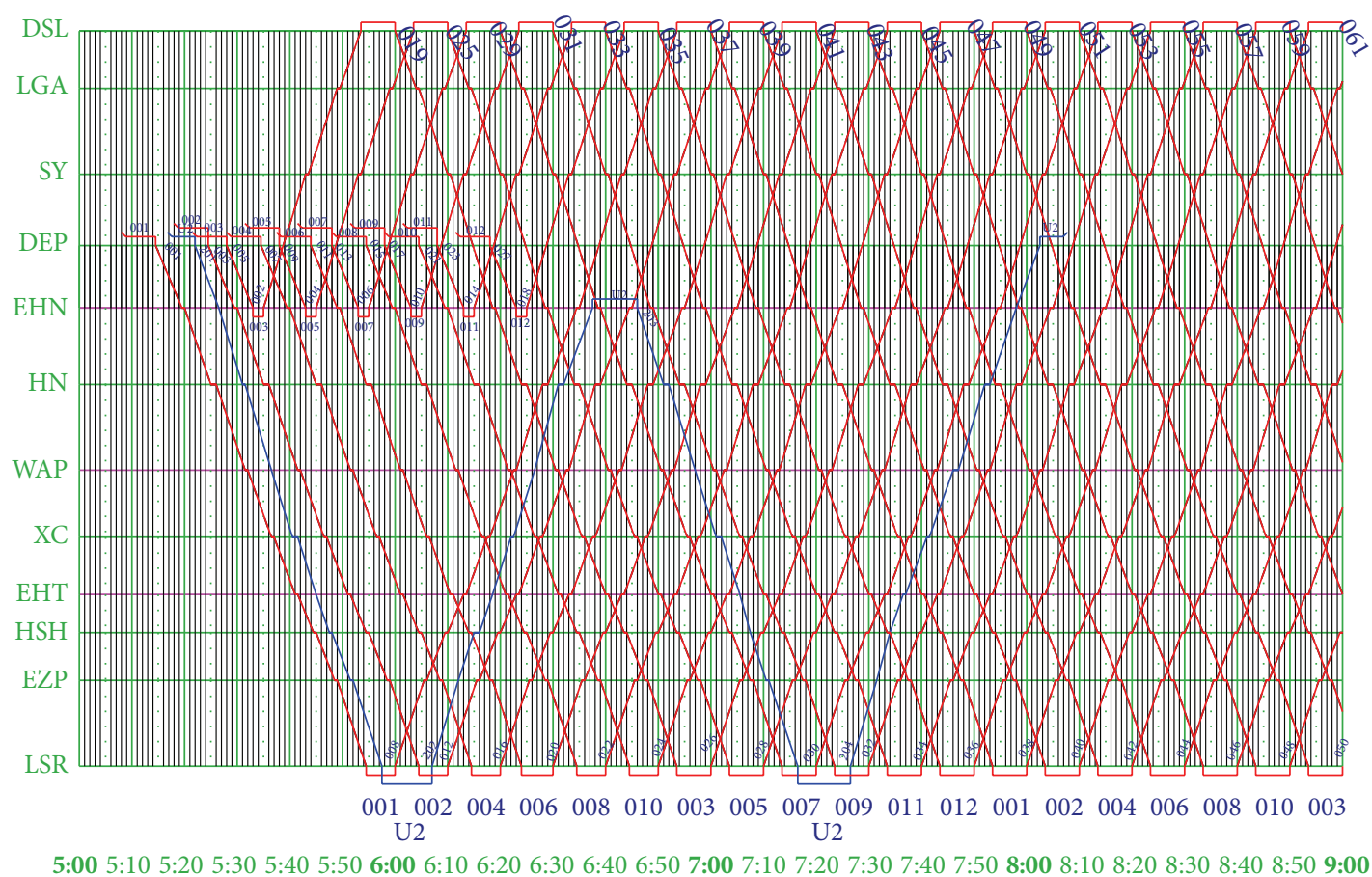

FIGURE 8: Time-distance diagram obtained by the scenario 2.

TABLE 5: Different scenarios.

\begin{tabular}{|c|c|c|c|c|}
\hline Scenarios ID & Objectives $\left(F_{t}\right.$ or $\left.F_{s}\right)$ & Maximum deviation $\left(d t_{i}\right)$ & New TU ID & Time window scheme ID \\
\hline 1 & $\min F_{t}$ & $0 \mathrm{sec}$ & $\mathrm{U} 2$ & TW3 \\
\hline 2 & $\min F_{t}$ & $0 \mathrm{sec}$ & $\mathrm{U} 2$ & TW4 \\
\hline 3 & $\min F_{s}$ & $300 \mathrm{sec}$ & $\mathrm{U} 1$ & TW1 \\
\hline 4 & $\min F_{s}$ & $300 \mathrm{sec}$ & $\mathrm{U} 1$ & TW2 \\
\hline 5 & $\min F_{s}$ & $270 \mathrm{sec}$ & $\mathrm{U} 1$ & TW2 \\
\hline 6 & $\min F_{s}$ & $240 \mathrm{sec}$ & $\mathrm{U} 1$ & TW2 \\
\hline 7 & $\min F_{s}$ & $210 \mathrm{sec}$ & U1 & TW2 \\
\hline 8 & $\min F_{s}$ & $180 \mathrm{sec}$ & U1 & TW2 \\
\hline 9 & $\min F_{s}$ & $150 \mathrm{sec}$ & $\mathrm{U} 1$ & TW2 \\
\hline 10 & $\min F_{s}$ & $120 \mathrm{sec}$ & U1 & TW2 \\
\hline
\end{tabular}

TABLE 6: Computation results of the scenarios.

\begin{tabular}{lcc}
\hline Scenario ID & Objective value & Solution time (second) \\
\hline 1 & 265 & 3 \\
2 & 265 & 2 \\
3 & 119 & 52 \\
4 & 139 & 10 \\
5 & 139 & 12 \\
6 & 139 & 13 \\
7 & 139 & 15 \\
8 & 146 & 9 \\
9 & 160 & 8 \\
10 & & No solution \\
\hline
\end{tabular}

Scenarios 4-7 have the same objective values and output the same new timetable from computation; also the maximum deviation time of initial timetable is not less than $210 \mathrm{sec}$ in the case of adding $\mathrm{U} 1$ at the time window TW2. The objective value of scenario 9 is $160 \mathrm{sec}$. Scenario 10 has no solution, which means that no new train can be inserted in the initial timetable, since the maximum turnback capacity of DSL has been reached; that is, the maximum deviation time approaches $120 \mathrm{sec}$.

It implies that $150 \mathrm{sec}$ is the minimum deviation time on the condition of successfully inserting the trains of U1. Figure 11 shows the detailed train line in DSL of scenarios 4 and 9; these figures illustrate that train "004" moves to the right for $210 \mathrm{sec}$ and train " 019 " moves to the left for $60 \mathrm{sec}$ at 


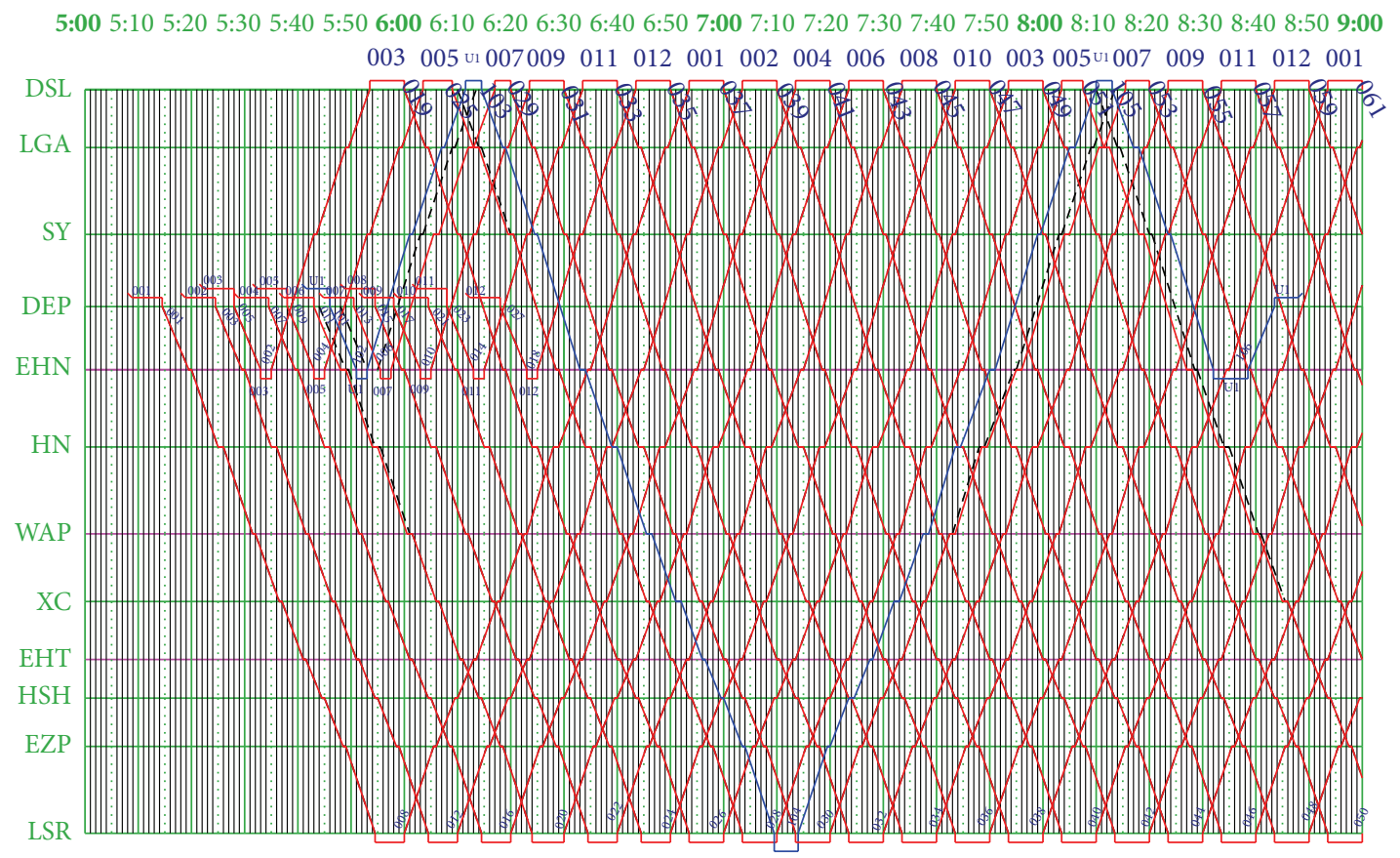

001002004006008010003005007009011012001002004006008010003

5:00 5:10 5:20 5:30 5:40 5:50 6:00 6:10 6:20 6:30 6:40 6:50 7:00 7:10 7:20 7:30 7:40 7:50 8:00 8:10 8:20 8:30 8:40 8:50 9:00

FIgURE 9: Time-distance diagram obtained by the scenario 3 (the dotted lines are the initial trains).

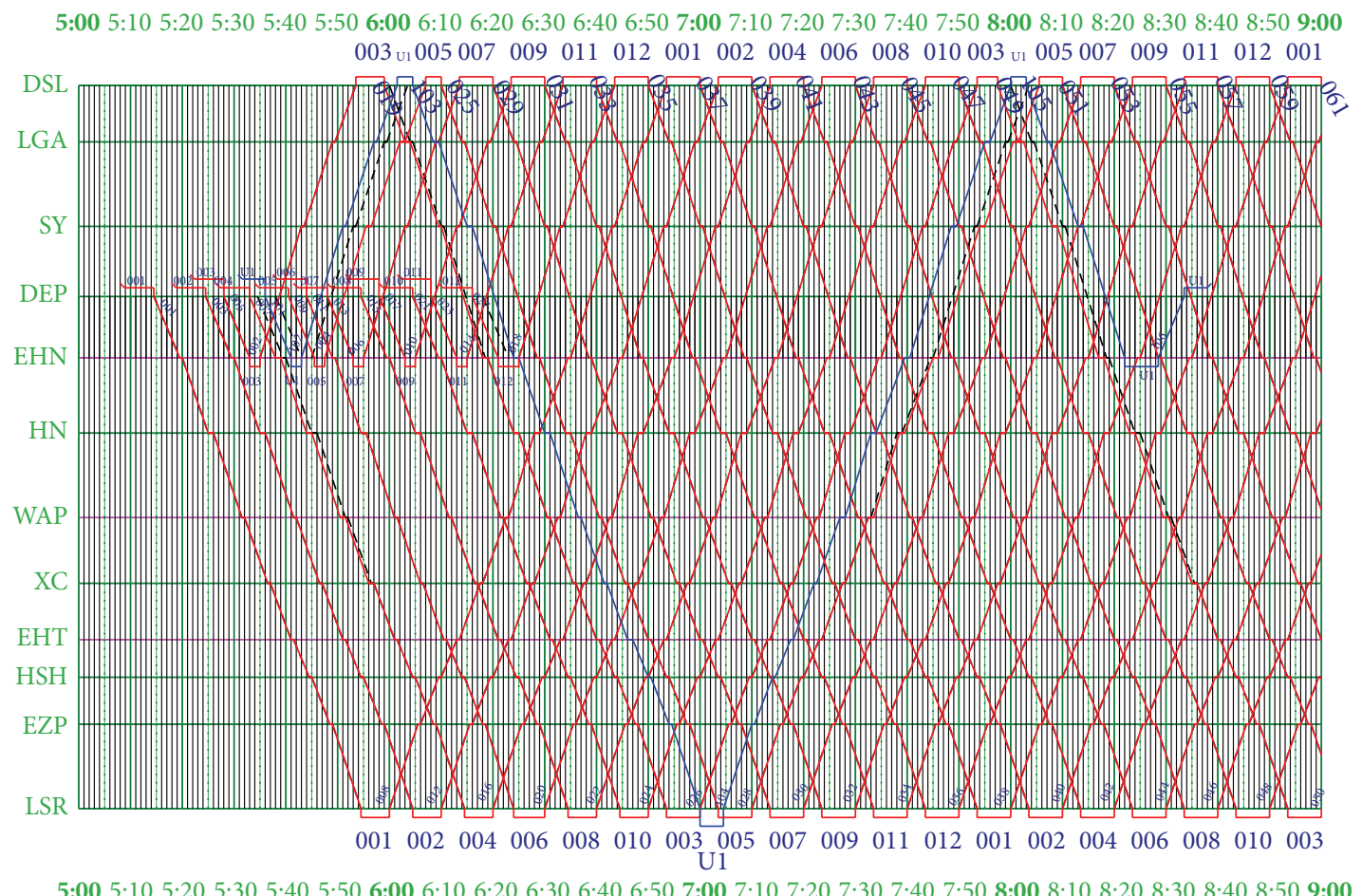

FIGURE 10: Time-distance diagram obtained by the scenario 4 (the dotted lines are the initial trains). 


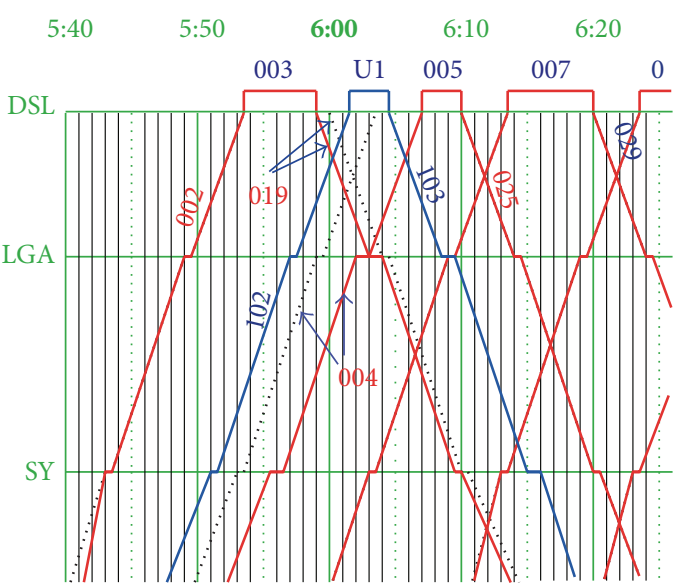

(a)

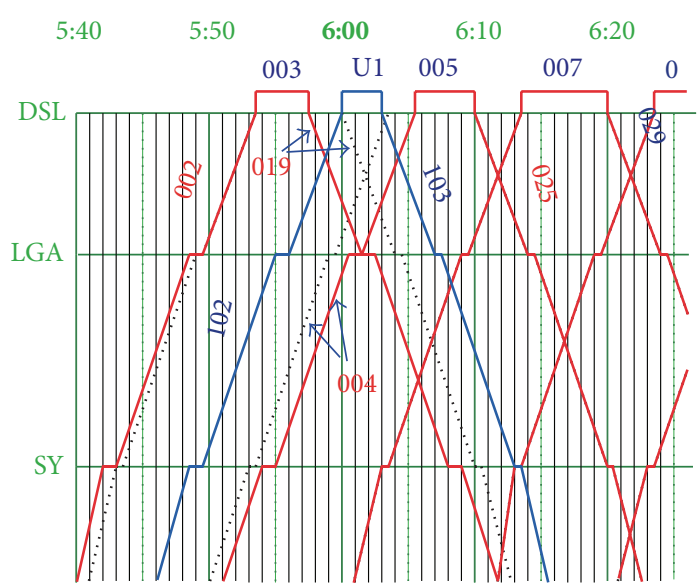

(b)

FIGURE 11: Time-distance diagram obtained by the scenarios 4 (a) and 9 (b) (the dotted lines are the initial trains).

DSL as the maximum deviation time is $300 \mathrm{sec}$ (scenario 4), but in scenario 9 (the maximum deviation time is $150 \mathrm{sec}$ ), train " 004 " needs to move right for $120 \mathrm{sec}$ and train " 019 " needs to move left for $150 \mathrm{sec}$ at DSL.

\section{Conclusions and Future Work}

In this paper, a model and problem formulation for scheduling additional TU services have been proposed. The main contribution of the paper is consideration of the timetable scheduling and the TUs scheduling together as an integrated optimization model with two objectives according to section and terminal capacities. Additionally a maximum deviation for arrival or departure times of trains in initial timetable, the strategy of slow services stopping at all stations and express services stopping only at some special stations, the linking order, and time window of new inserted trains are also considered in the model. The developed model is a generic one that can be easily modified to adapt any changes in initial timetable or any new scheme of inserting trains linked by TUs. The given example illustrates that rail transit agencies can obtain a reasonable new timetable for different administrative goals in a matter of seconds and shows that the model is well suited to be used in daily operations.

However, the proposed model is not a multiobjective one; in many real situations, creating an appropriate new timetable means finding a balance between several objectives such as the composition of minimum $F_{t}$ and $F_{s}\left(F_{t+s}=F_{t} \cdot \alpha_{1}+F_{s} \cdot \alpha_{2}\right)$, where the coefficients of $\alpha_{1}$ and $\alpha_{2}$ are hard to evaluate. On the other hand, long planning horizon and large number of new trains needed to be inserted will make the computation time longer. In order to improve the service level, another objective that should be taken into account is how to obtain a regular timetable which has equal intervals between trains after adding new ones. These issues will be addressed in future researches.

\section{Conflict of Interests}

The authors declare that there is no conflict of interests regarding the publication of this article.

\section{Acknowledgments}

This work was supported by (1) the National Natural Science Foundation of China (Grant nos. 61473210, 51008229, 51208381, and 71071112), (2) the Fundamental Research Funds for the Central Universities (Grant no. 20123228), (3) iRAGS of Siemens AG in Braunschweig, and (4) The Scientific and Technological Research Council of Turkey (TÜBİTAK). The acquisition of the analysis data in the paper is supported by the Shanghai Shentong Metro Operation Management Center. The authors appreciate this support.

\section{References}

[1] V. Vuchic, Urban Transit Operations, Planning and Economics, American Society of Civil Engineers, Reston, Va, USA, 2005.

[2] L. Cadarso and Á. Marín, "Integration of timetable planning and rolling stock in rapid transit networks," Annals of Operations Research, vol. 199, pp. 113-135, 2012.

[3] A. Caprara, L. Kroon, M. Monaci et al., "Passenger railway optimization," in Handbooks in Operations Research and Management Science, pp. 129-187, Elsevier, San Diego, Calif, USA, 2007.

[4] V. Cacchiani, D. Huisman, M. Kidd, L. Kroon, P. Toth, and L. Veelenturf, "An overview of recovery models and algorithms for real-time railway rescheduling," Transportation Research B: Methodological, vol. 63, pp. 15-37, 2014.

[5] V. Guihaire and J. K. Hao, "Transit network design and scheduling: a global review," Transportation Research A: Policy and Practice, vol. 42, no. 10, pp. 1251-1273, 2008.

[6] A. Ceder, "Public-transport automated timetables using even headway and even passenger load concepts," in Proceedings of 
the 32nd Australasian Transport Research Forum (ATRF '09), October 2009.

[7] Z. Jiang, J. Gao, and R. Xu, "Circle rail transit line timetable scheduling using Rail TPM," in Proceedings of the 12th International Conference on Computer System Design and Operation in the Railways and Other Transit Systems (COMPRAIL '10), pp. 945-952, August-September 2010.

[8] Z. Jiang, R. Xu, Q. Wu, and J. Lv, "Shared-path routing timetable computer designing in rail transit system," Journal of Tongji University, vol. 38, no. 5, pp. 692-696, 2010.

[9] H. Niu and X. Zhou, "Optimizing urban rail timetable under time-dependent demand and oversaturated conditions," Transportation Research C: Emerging Technologies, vol. 36, pp. 212230, 2013.

[10] M. Freyss, R. Giesen, and J. C. Muñoz, "Continuous approximation for skip-stop operation in rail transit," Transportation Research C: Emerging Technologies, vol. 36, pp. 419-433, 2013.

[11] A. Alfieri, R. Groot, L. Kroon, and A. Schrijver, "Efficient circulation of railway rolling stock," Transportation Science, vol. 40, no. 3, pp. 378-391, 2006.

[12] P. Fioole, L. Kroon, G. Maróti, and A. Schrijver, "A rolling stock circulation model for combining and splitting of passenger trains," European Journal of Operational Research, vol. 174, no. 2, pp. 1281-1297, 2006.

[13] L. Cadarso, Á. Marín, and G. Maróti, "Recovery of disruptions in rapid transit networks," Transportation Research E: Logistics and Transportation Review, vol. 53, no. 1, pp. 15-33, 2013.

[14] Z. Lin and R. S. K. Kwan, "A two-phase approach for real-world train unit scheduling," Public Transport, 2013.

[15] X. J. Eberlein, N. H. M. Wilson, C. Barnhart, and D. Bernstein, "The real-time deadheading problem in transit operations control," Transportation Research B: Methodological, vol. 32, no. 2, pp. 77-100, 1997.

[16] A. Haghani and M. Banihashemi, "Heuristic approaches for solving large-scale bus transit vehicle scheduling problem with route time constraints," Transportation Research Part A: Policy and Practice, vol. 36, no. 4, pp. 309-333, 2002.

[17] A. Haghani, M. Banishashemi, and K. Chiang, "A comparative analysis of bus transit vehicle scheduling models," Transportation Research B: Methodological, vol. 37, no. 4, pp. 301-322, 2003.

[18] B. Yu, Z. Yang, and S. Li, "Real-time partway deadheading strategy based on transit service reliability assessment," Transportation Research A: Policy and Practice, vol. 46, no. 8, pp. 12651279, 2012.

[19] R. L. Burdett and E. Kozan, “Techniques for inserting additional trains into existing timetables," Transportation Research B: Methodological, vol. 43, no. 8-9, pp. 821-836, 2009.

[20] H. Flier, T. Graffagnino, and M. Nunkesser, "Scheduling additional trains on dense corridors," in Experimental Algorithms, vol. 5526 of Lecture Notes in Computer Science, pp. 149-160, 2009.

[21] D. Canca, E. Barrena, A. Zarzo, F. Ortega, and E. Algaba, "Optimal train reallocation strategies under service disruptions," Procedia-Social and Behavioral Sciences, vol. 54, pp. 402-413, 2012. 


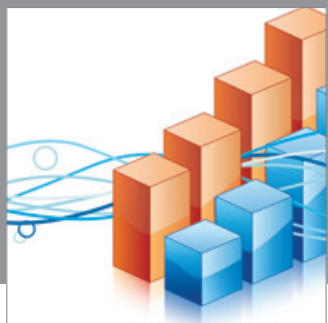

Advances in

Operations Research

mansans

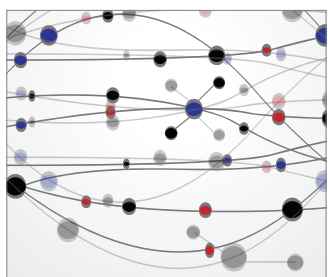

The Scientific World Journal
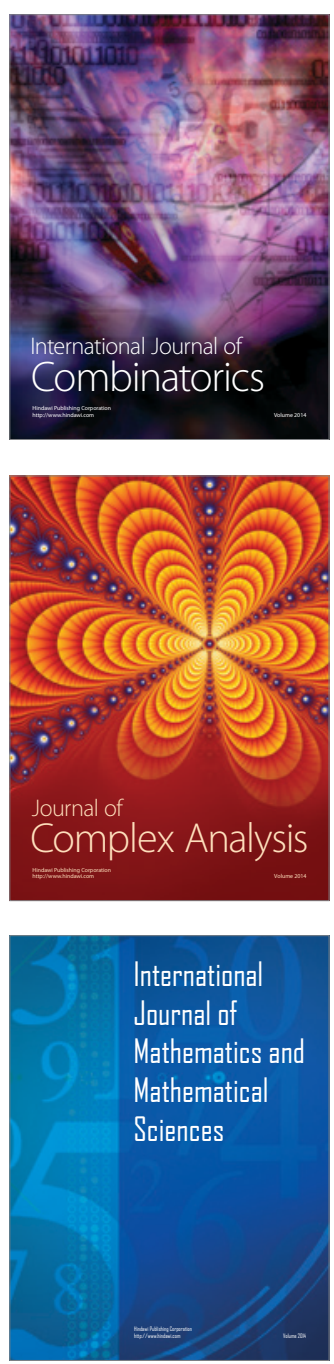
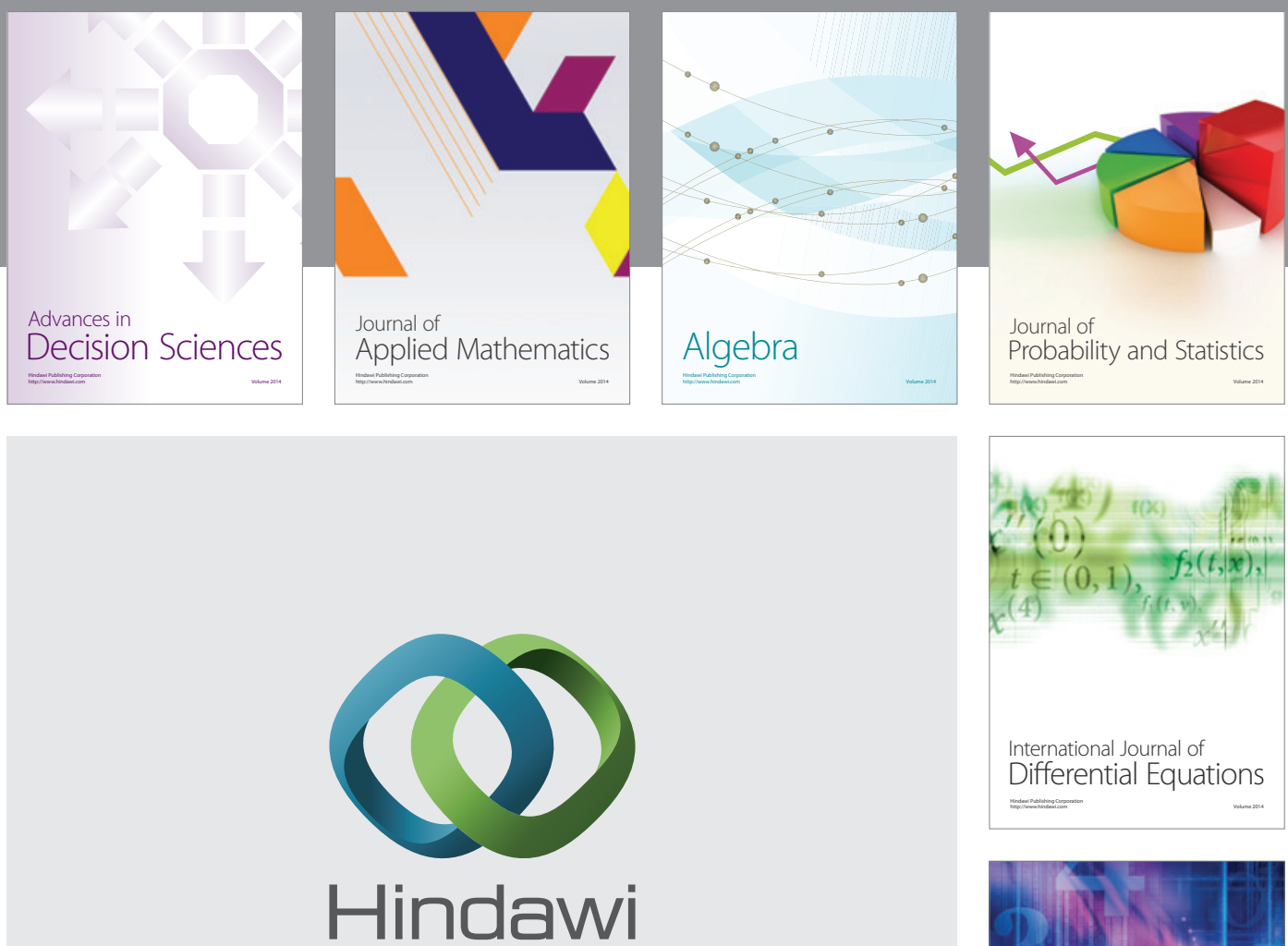

Submit your manuscripts at http://www.hindawi.com
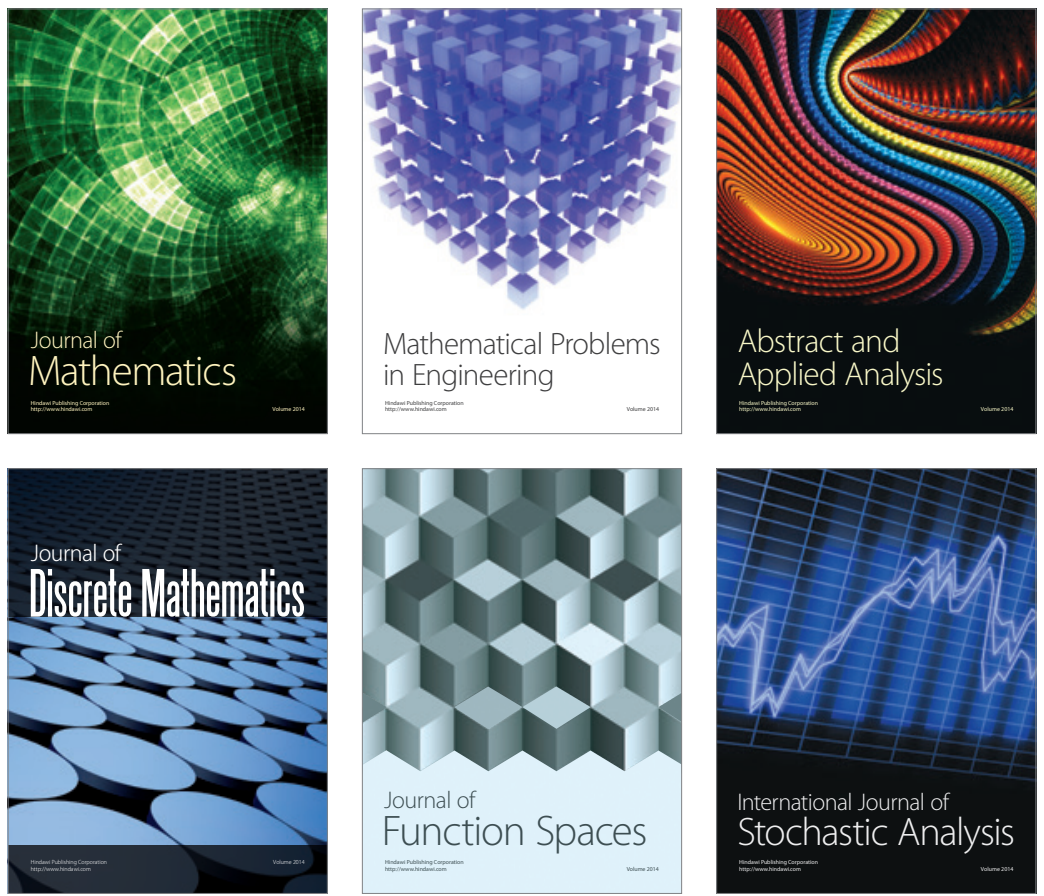

Journal of

Function Spaces

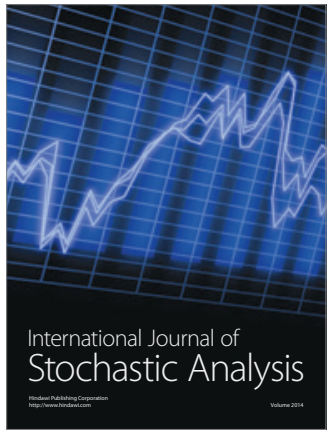

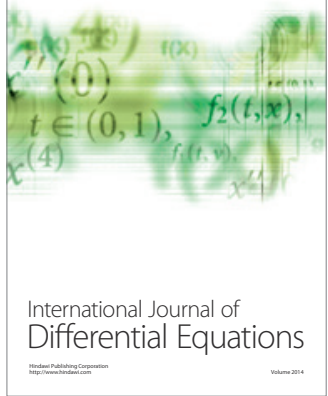
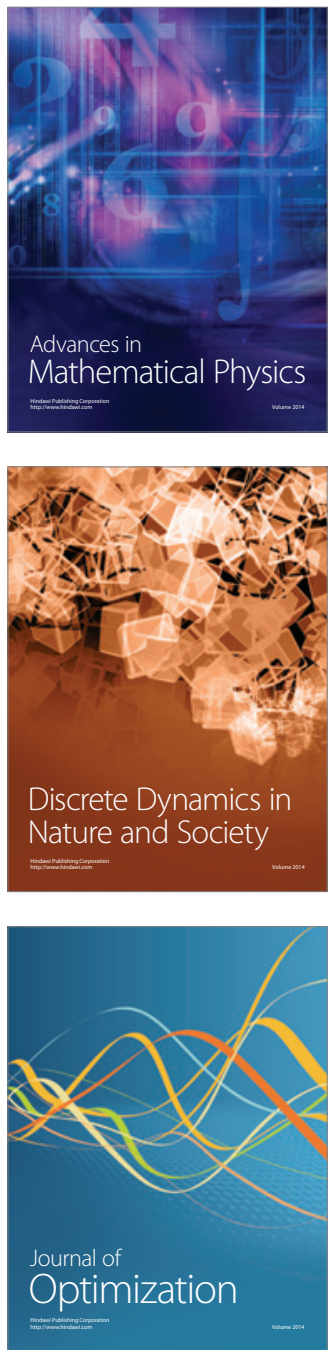